Article

\title{
Cross-Sectional Survey of the Amount of Sugar and Energy in Chocolate Confectionery Sold in the UK in 1992 and 2017
}

\author{
Kawther M. Hashem *, Feng J. He, Sarah A. Alderton and Graham A. MacGregor \\ Wolfson Institute of Preventive Medicine, Barts and The London School of Medicine \& Dentistry, Queen Mary \\ University of London, Charterhouse Square, London EC1M 6BQ, UK \\ * Correspondence: k.hashem@qmul.ac.uk; Tel.: +44-(0)20-7882-6219
}

Received: 20 June 2019; Accepted: 31 July 2019; Published: 3 August 2019

check for updates

\begin{abstract}
The study aimed to compare the sugar $(1992,2017)$ and energy $(2017)$ content of chocolate confectionery available in the UK between 1992 and 2017 using cross-sectional surveys. All major UK retailers operating at the time were included. Sugar content in 1992 was obtained from a booklet and sugar and energy content from 2017 were collected from product packaging in-store. In 1992, the average sugar content of chocolate confectionery was $46.6 \pm 10.3 \mathrm{~g} / 100 \mathrm{~g}$ and in 2017 it was $47.3 \pm 12.1 \mathrm{~g} / 100 \mathrm{~g}$. Sugar content ranged from 0.5 to $75.2 \mathrm{~g} / 100 \mathrm{~g}$, with large variations between different categories of chocolate and within the same category of chocolate. There were 23 products found in both 1992 and 2017. The average sugar content per $100 \mathrm{~g}$ for these products was $44.6 \pm 9.4 \mathrm{~g}$ in 1992 and $54.7 \pm 6.3 \mathrm{~g}$ in 2017, representing a $23 \%$ increase in sugar content $(p<0.001)$. The results show that the sugar content of chocolate confectionery has increased since 1992, which is concerning. However, they also suggest sugar levels can be reduced because (a) lower sugar versions of the same products existed in 1992 and (b) there is a large variation in sugar and energy content between different categories of chocolate and within the same category in 2017.
\end{abstract}

Keywords: sugars; chocolate confectionery; reformulation

\section{Introduction}

In July 2015, the Scientific Advisory Committee on Nutrition (SACN) in the UK recommended that average free sugars (sugar) intake, across the UK population, should not exceed $5 \%$ of total energy intake [1]. SACN's advice was based on the need to reduce obesity, type 2 diabetes and dental caries risk [2-10].

In 2014, average intakes of sugar exceeded recommendations in all age groups [11]. The mean sugar intake in adults was 60 g per day, equivalent to $12 \%$ of daily energy intake. In children, the average sugar intake was $54 \mathrm{~g}(13 \%)$ per day in $4-10$ year olds and $73 \mathrm{~g}(15 \%)$ per day in $11-18$ year olds [11].

In order to reduce sugar intake (and therefore obesity and tooth decay) and help consumers to follow the principles of the Eatwell guide, the UK government published Childhood Obesity: A Plan for Action (2016), in which a reformulation programme for sugar was included. The programme, led by Public Health England, asked manufacturers to reduce sugar by $20 \%$ by 2020 in each of the nine food and drink categories that contribute the most sugar in children's diets, such as breakfast cereals, yoghurts, cakes, biscuits, morning goods, puddings, sweet spreads, sweet confectionery, ice cream and chocolate confectionery.

As part of the sugar reduction programme, companies can choose to achieve the $20 \%$ reduction by reformulating their products (without increasing overall calories), reducing portion size or promoting 
their lower sugar products [12]. Sales weighted averages (SWA) were calculated by weighing the sugar level of individual products against their volume sales; a high-selling product with high sugar levels drives the SWA upwards, whereas a high selling product with a low sugar level drives it downwards. SWA for chocolate confectionery is currently $54.6 \mathrm{~g}$ of sugar per $100 \mathrm{~g}$, with the aim of bringing it down to $43.7 \mathrm{~g}$ by 2020 [12]. The SWA allows for flexibility in the sugar levels in different products within a category, e.g., a chocolate manufacturer can continue to sell a high sugar chocolate product if the remainder of their portfolio is lower. However, if the high sugar product is a big seller, the amount of sugar will have to be reduced through reformulation or reduced price promotions to reduce sales [12]. The calorie SWA was $200 \mathrm{kcal}$ per $100 \mathrm{~g}$ and the cap for a single serve of chocolate was set at a maximum of $250 \mathrm{kcal}$ [12].

This research aims to (a) compare sugar content in chocolate confectionery between 1992 and 2017, (b) evaluate the sugar and energy content of chocolate confectionery sold in the UK, (c) report the variability in sugar and energy content in 2017, (d) assess the sugar content in relation to the UK's new daily recommendation for sugar intake and by chocolate manufacturers in the UK in 1992 and 2017 and (e) compare current serving sizes to the maximum calorie cap of $250 \mathrm{kcal}$ suggested in the sugar reduction programme.

\section{Materials and Methods}

\subsection{Data Collection}

The sugar content from 1992 was obtained from a booklet published in 1992 by Octavo called A-Z of Shopping; Guide to Good Health. What's in your shopping basket? The sugar and energy content from 2017 was collected from product packaging in one large outlet in London for each of the major UK supermarket chains (Aldi, Asda, Lidl, Marks and Spencer, Morrisons, Sainsbury's, Tesco, The Co-operative and Waitrose). These supermarkets collectively hold over $93 \%$ of the grocery market share [13]. For each product in 2017, the data collected included the company name, product name, pack weight, portion/serving size, total sugars (g) and energy (kcal) per $100 \mathrm{~g}$ and per portion/serving. Data on total energy ( $\mathrm{kcal}$ ) content was collected to encompass the fat, carbohydrate, protein and sugar contents of products.

It was assumed that the 'total sugars' on the nutrition label of products represented the 'free sugars' content in chocolate confectionery. However, the definition of free sugars is new and not aligned with current claims and nutrition labelling on packaging. Free sugars includes all monosaccharides and disaccharides added to foods by the manufacturer, cook or consumer, plus sugars naturally present in honey, syrups and unsweetened fruit juices. It excludes lactose when naturally present in milk and milk products, as well as sugars contained within the cellular structure of foods (i.e., whole fruits and vegetables). Therefore, without the recipes of products, it is difficult to estimate the actual free sugars content of products that contain milk and/or dried fruit, but it was used as a proxy for free sugars anyway.

\subsection{Product Categories}

Products in 2017 were categorised by type (Table 1). The products were also categorised separately into the supermarkets' own labels and brands and by manufacturer (if they had more than five products in both 1992 and 2017). Some products contributed to the manufacturer average sugar content and overall results but not to the category results, because they did not fit into a specific category and there were too few products to set a specific category for those products (Appendix A). Within 'single serve' products, duo products were included, since it was assumed that most consumers would consume both servings on one occasion (applied to one product). To check the accuracy of the data, each category was screened for outliers; the lowest and highest values in each category were checked with the original pack photos. 
Table 1. Descriptions and examples of chocolate confectionery categories.

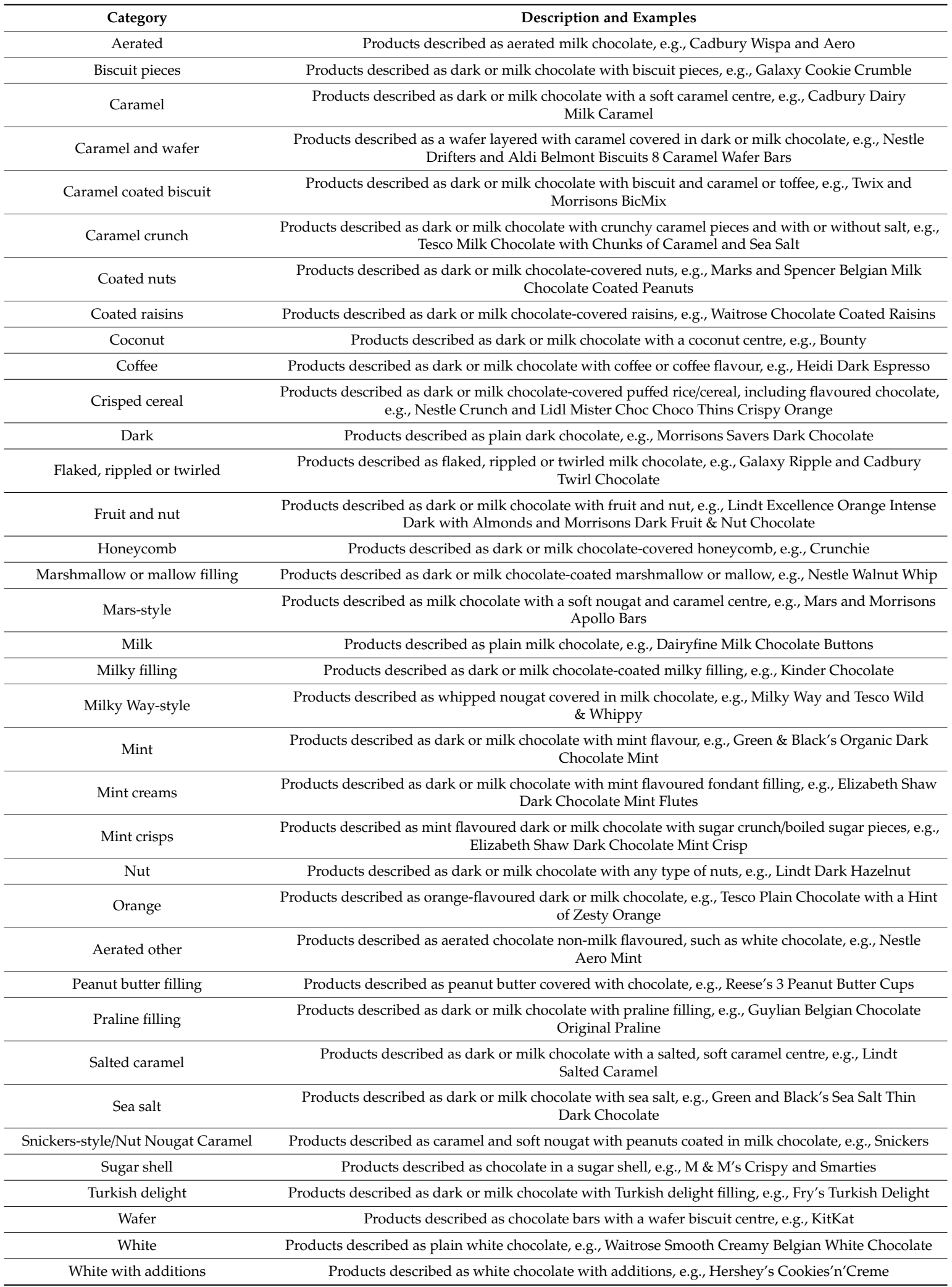

\subsection{Inclusion/Exclusion Criteria}

We included all chocolate except for selection/assortment boxes, seasonal products, such as Easter eggs, advent calendars and chocolate bunnies/snowmen/reindeer, and chocolate containing alcohol. 


\subsection{Analysis}

Per $100 \mathrm{~g}$ : Some brands sell the same formulation in different pack sizes. The $100 \mathrm{~g}$ data used in the study only included one example, regardless of the different pack sizes. However, sometimes the product name was the same, which implied it was the same formulation/product, but the products seemed to have different nutritional contents per $100 \mathrm{~g}$. In such cases, the products were different formulations and therefore considered as separate products.

Per serving: The per serving data included all the different per serving/chocolate/portion information available, or pack size (if one pack was equal to single serve).

High, medium and low criteria for sugar content: The sugar content was compared to the UK front-of-pack colour-coded labelling criteria for foods. Colour coding for total sugar was based on the following thresholds: Red/high $>27 \mathrm{~g} /$ portion or $>22.5 \mathrm{~g} / 100 \mathrm{~g}$, amber/medium $>5.0$ to $\leq 22.5 \mathrm{~g} / 100 \mathrm{~g}$ and green/low $\leq 5.0 \mathrm{~g} / 100 \mathrm{~g} \mathrm{[14]}$.

Maximum sugar intake: The sugar content was also compared to the maximum daily recommendation for sugar intake for adults ( $30 \mathrm{~g} /$ day) and 7-10 year-old children ( $24 \mathrm{~g} /$ day) [14].

Calorie cap: The energy content per serving was compared to the maximum calorie cap of $250 \mathrm{kcal}$ suggested in the sugar reduction programme.

Manufacturers: the sugar and energy contents were compared between supermarkets' own labels and branded manufactures and by individual manufacturers to assess manufacturers' current average levels.

\subsection{Statistical Analysis}

A comparison was made between supermarkets' own labels and branded products for sugar. The Mann-Whitney U test was used when the sample size was small and the data were not normally distributed (i.e. for 1992) and an independent samples t-test was used when the sample size was large and the data were normally distributed (i.e. for 2017).

For the purpose of assessing sugar levels in the same products since 1992, only products with data available in both years were included in this analysis. A paired $t$-test was used to examine whether there was a significant change in the sugar content from 1992 to 2017.

Data were reported as means, standard deviations (SDs) and ranges, as indicated. Significance in all tests carried out was deemed significant as being $p<0.05$. The data were analysed using IBM SPSS software, Version 25 (Armonk, NY, USA).

\section{Results}

\subsection{Sugar per $100 \mathrm{~g}$ in 1992}

A total of 44 products were included in the per $100 \mathrm{~g}$ analysis. The average sugar content was $46.6 \pm 10.3 \mathrm{~g} / 100 \mathrm{~g}$. Branded chocolate confectionery had a slightly higher sugar content compared with supermarkets' own labels ( $47.8 \mathrm{~g}$ vs. $44.8 \mathrm{~g}, p=0.173)$, but the difference was not statistically significant. All of the chocolate products would receive a 'red' (high) front-of-pack label for sugar.

Among the manufacturers with five or more chocolate products in this study, Nestle's product range contained the highest average sugar content and Marks and Spencer's contained the lowest (Table 2).

Table 2. Sugar content in chocolate confectionery by manufacturer per $100 \mathrm{~g}$ in 1992.

\begin{tabular}{ccc}
\hline Manufacturer & N & Sugars $(g)$ Mean \pm SD (Range) \\
\hline Own label & 18 & $44.8(22.9-74.8)$ \\
Branded & 26 & $47.8(27.0-60.0)$ \\
Nestle & 8 & $53.7 \pm 3.0(50.0-59.0)$ \\
Sainsbury's & 9 & $45.3 \pm 14.2(22.9-74.8)$ \\
Mondelez International & 18 & $45.2 \pm 9.9(27.0-60.0)$ \\
Marks and Spencer & 8 & $43.4 \pm 9.7(33.0-62.3)$ \\
\hline
\end{tabular}




\subsection{Nutrient Content in 2017}

A total of 617 products met the inclusion criteria.

\subsubsection{Sugar and Energy per $100 \mathrm{~g}$ in 2017}

A total of 527 products were included in the per $100 \mathrm{~g}$ analysis. Figure 1 and Table 3 show the sugar content in different categories of chocolate per $100 \mathrm{~g}$. The average sugar content was $47.3 \pm 12.1 \mathrm{~g} / 100 \mathrm{~g}$. There was a large variation in sugar content between different categories of chocolate and within the same category of chocolate, ranging from 0.5 to $75.2 \mathrm{~g} / 100 \mathrm{~g}$. Overall, $95 \%$ of chocolate products would receive a 'red' (high) front-of-pack label for sugar.

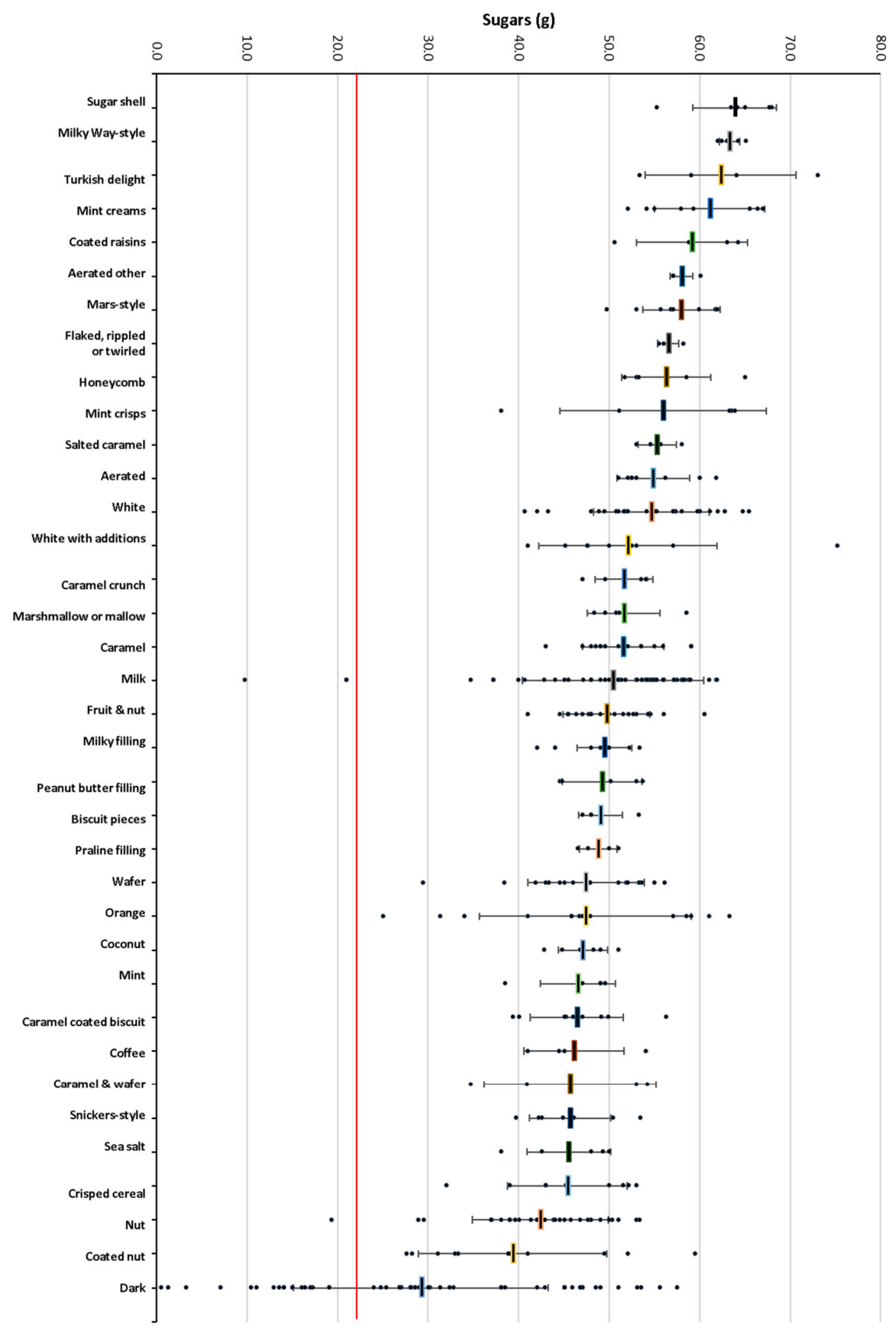

Figure 1. Sugar contents of different categories of chocolate confectionery in 2017 (g/100 g). The red line denotes red (high) criteria for sugar (>11.25 g). Values are individual products within each category (circle) with their means (rectangle) and standard errors represented by vertical bars. 
Table 3. Sugar and energy contents of different categories of chocolate confectionery per $100 \mathrm{~g}$ in 2017.



Figure 2 and Table 3 show the energy contents per $100 \mathrm{~g}$ in different categories of chocolate. The average energy content in chocolate products was $533 \pm 49 \mathrm{kcal} / 100 \mathrm{~g}$. There was a large variation in energy content between different categories of chocolate and within the same category of chocolate, ranging from 121 to $647 \mathrm{kcal} / 100 \mathrm{~g}$. On average, nut chocolate (570 $\pm 25 \mathrm{kcal} / 100 \mathrm{~g}$ ) contained the highest amounts of energy and ranged from 499 to $628 \mathrm{kcal}$. 


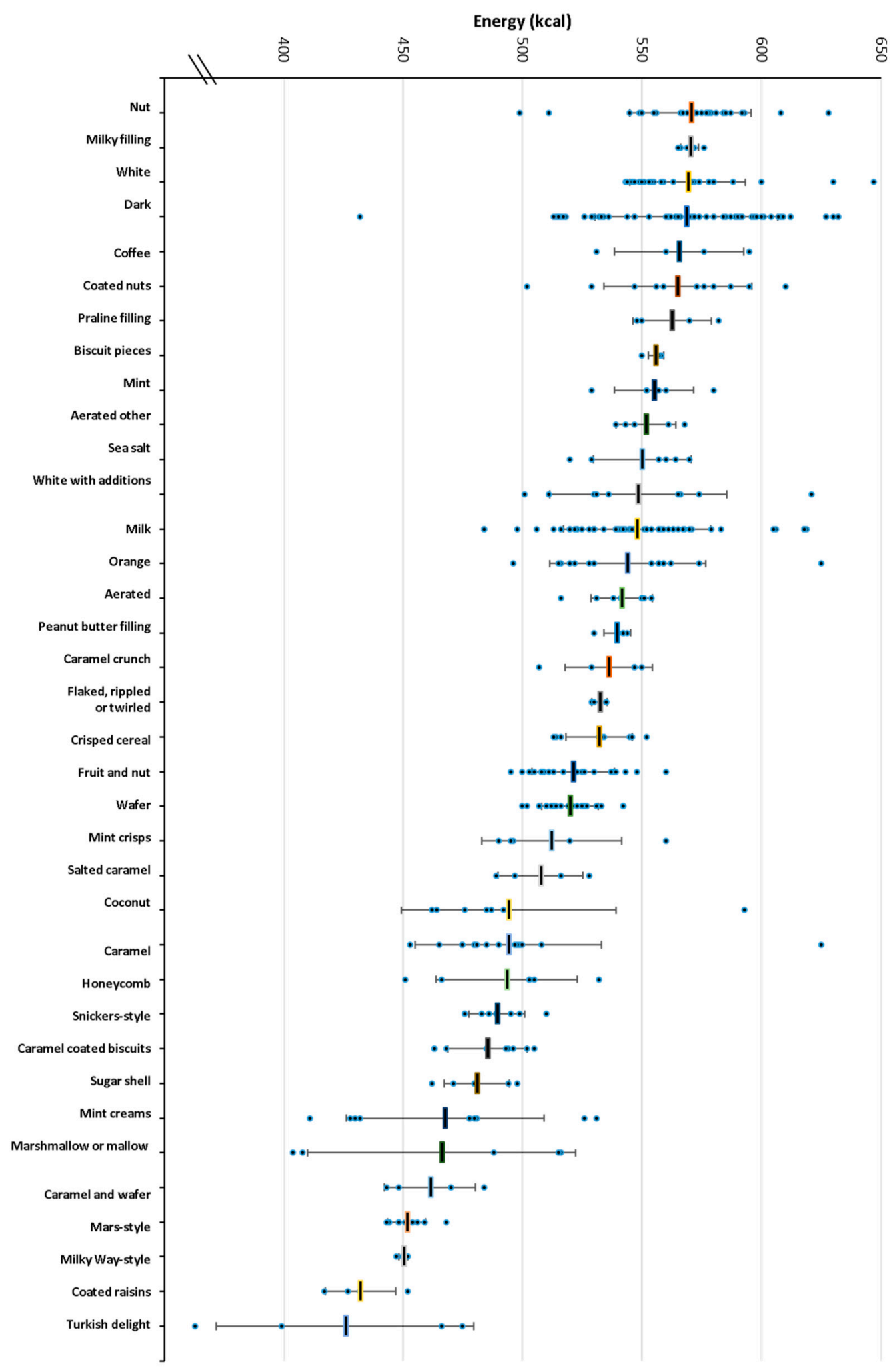

Figure 2. Energy contents of different categories of chocolate confectionery in 2017 (kcal/100 g). Values are individual products within each category (circle) with their means (rectangle) and standard errors represented by vertical bars. 


\subsubsection{Sugar and Energy per Serving in 2017}

A total of 469 products provided nutritional information per serving/portion/chocolate. Serving size varied between different categories of chocolate confectionery and within the same category and ranged from 4.3 to $86 \mathrm{~g}$. Among the single serve products, the serving size ranged from 14 to $55 \mathrm{~g}$, while among the sharing bags format, the serving size ranged from 16 to $48 \mathrm{~g}$. In the block chocolate format, the serving size ranged from 7 to $86 \mathrm{~g}$.

The mean sugar content in chocolate confectionery was $12.9 \pm 6.1 \mathrm{~g} / \mathrm{serving}$. Chocolate-coated Turkish Delight contained the highest sugar content per serving (25.2 $\pm 13.3 \mathrm{~g})$, almost an adult's entire maximum daily intake of sugar (Table 4).

Table 4. Sugar and energy contents in different categories of chocolate confectionery per serving in 2017.

\begin{tabular}{|c|c|c|c|c|c|}
\hline Category & $\mathbf{N}$ & $\begin{array}{c}\text { Sugars (g) Mean } \pm \\
\text { SD (Range) }\end{array}$ & Category & $\mathbf{N}$ & $\begin{array}{c}\text { Energy (kcal) Mean } \pm \\
\text { SD (Range) }\end{array}$ \\
\hline \multicolumn{6}{|l|}{ Descending order } \\
\hline Turkish Delight & 4 & $25.2 \pm 13.3(13.3-40.2)$ & Peanut butter filling & 4 & $222 \pm 62(135-277)$ \\
\hline Sugar shell & 6 & $20.8 \pm 8.4(9.0-29.4)$ & $\begin{array}{c}\text { Snickers-style/nut nougat } \\
\text { Caramel }\end{array}$ & 8 & $204 \pm 28(171-250)$ \\
\hline Coated raisins & 4 & $19.6 \pm 6.3(12.7-25.2)$ & Caramel-coated biscuit & 9 & $181 \pm 63(93-293)$ \\
\hline Peanut butter filling & 4 & $19.6 \pm 5.1(13.3-25.6)$ & Praline filling & 3 & $172 \pm 51(114-210)$ \\
\hline $\begin{array}{c}\text { Snickers-style/nut } \\
\text { nougat Caramel }\end{array}$ & 8 & $19.0 \pm 3.2(15.1-24.7)$ & White with additions & 7 & $164 \pm 68(88-233)$ \\
\hline Honeycomb & 6 & $17.9 \pm 2.8(14.6-21.5)$ & Turkish Delight & 4 & $160 \pm 51(117-220)$ \\
\hline Mars-style & 10 & $17.5 \pm 6.3(10.0-25.6)$ & Sugar shell & 6 & $159 \pm 68(66-232)$ \\
\hline Caramel-coated biscuit & 9 & $17.2 \pm 5.8(7.9-27.3)$ & Honeycomb & 6 & $158 \pm 33(126-209)$ \\
\hline Salted caramel & 3 & $16.8 \pm 4.3(14.1-21.8)$ & Coated nuts & 9 & $156 \pm 42(117-232)$ \\
\hline $\begin{array}{l}\text { Marshmallow or mallow } \\
\text { filling }\end{array}$ & 5 & $16.1 \pm 1.9(13.9-18.4)$ & Caramel crunch & 3 & $154 \pm 58(106-219)$ \\
\hline $\begin{array}{l}\text { Flaked, rippled or } \\
\text { twirled }\end{array}$ & 4 & $15.8 \pm 3.3(12.0-19.2)$ & Salted caramel & 3 & $153 \pm 50(122-211)$ \\
\hline White with additions & 7 & $15.6 \pm 6.7(8.3-26.3)$ & Nut & 24 & $152 \pm 57(53-243)$ \\
\hline Caramel & 14 & $15.2 \pm 4.5(9.4-24.1)$ & Caramel and cereal & 3 & $150 \pm 42(124-198)$ \\
\hline Caramel crunch & 3 & $14.9 \pm 5.7(10.8-21.4)$ & Flaked, rippled or twirled & 4 & $148 \pm 29(115-175)$ \\
\hline Praline filling & 3 & $14.8 \pm 4.7(9.3-17.9)$ & Milk & 53 & $147 \pm 58(30-282)$ \\
\hline Coconut & 6 & $14.7 \pm 5.4(10.7-25.5)$ & Fruit and nut & 20 & $147 \pm 42(84-249)$ \\
\hline Caramel and cereal & 3 & $14.5 \pm 4.1(11.7-19.1)$ & Coconut & 6 & $147 \pm 42(119-231)$ \\
\hline Fruit and nut & 20 & $14.2 \pm 4.5(9.1-26.0)$ & $\begin{array}{l}\text { Marshmallow or mallow } \\
\text { filling }\end{array}$ & 5 & $145 \pm 18(127-171)$ \\
\hline Mint creams & 8 & $14.1 \pm 8.2(2.5-32.1)$ & Coated raisins & 4 & $142 \pm 38(107-181)$ \\
\hline Aerated & 8 & $13.9 \pm 4.5(5.1-18.7)$ & Caramel & 14 & $141 \pm 44(95-244)$ \\
\hline Milk & 53 & $13.7 \pm 6.0(1.9-29.4)$ & Wafer & 20 & $140 \pm 51(87-228)$ \\
\hline White & 25 & $13.6 \pm 4.7(8.1-22.9)$ & White & 25 & $140 \pm 43(82-229)$ \\
\hline Milky Way-style & 6 & $12.7 \pm 1.9(9.9-14.1)$ & Aerated & 8 & $137 \pm 45(53-199)$ \\
\hline Wafer & 20 & $12.7 \pm 4.8(8.0-24.1)$ & Mars-style & 10 & $136 \pm 48(80-205)$ \\
\hline Orange & 11 & $12.1 \pm 5.1(6.3-21.4)$ & Crisped cereal & 10 & $136 \pm 32(103-221)$ \\
\hline Aerated other & 5 & $11.8 \pm 3.9(5.7-14.5)$ & Orange & 11 & $132 \pm 36(83-195)$ \\
\hline Crisped cereal & 10 & $11.6 \pm 3.6(8.0-21.2)$ & Mint & 5 & $123 \pm 17(110-145)$ \\
\hline Nut & 24 & $11.6 \pm 5.0(2.5-21.2)$ & Dark & 54 & $123 \pm 43(31-251)$ \\
\hline Coated nuts & 9 & $10.7 \pm 4.4(6.9-21.0)$ & Sea salt & 5 & $113 \pm 26(71-139)$ \\
\hline Caramel and wafer & 4 & $10.7 \pm 3.4(6.5-14.8)$ & Aerated other & 5 & $112 \pm 38(56-142)$ \\
\hline Mint & 5 & $10.2 \pm 1.9(7.7-12.3)$ & Biscuit pieces & 5 & $112 \pm 45(83-186)$ \\
\hline Biscuit pieces & 5 & $9.9 \pm 3.8(7.2-15.7)$ & Caramel and wafer & 4 & $108 \pm 30(71-134)$ \\
\hline Sea salt & 5 & $9.3 \pm 2.6(5.3-12.5)$ & Mint creams & 8 & $103 \pm 54(23-211)$ \\
\hline Milky filling & 7 & $8.2 \pm 2.5(3.0-11.2)$ & Milky filling & 7 & $95 \pm 28(33-119)$ \\
\hline Mint crisps & 3 & $7.9 \pm 3.5(4.0-10.6)$ & Coffee & 2 & $93 \pm 31(71-115)$ \\
\hline Coffee & 2 & $7.2 \pm 2.6(5.3-9.0)$ & Milky Way-style & 6 & $90 \pm 13(72-99)$ \\
\hline Dark & 54 & $6.7 \pm 4.4(0.1-19.4)$ & Mint crisps & 3 & $62 \pm 28(31-83)$ \\
\hline All products & 469 & $12.9 \pm 6.1(0.1-40.2)$ & All products & 469 & $142 \pm 53(5-494)$ \\
\hline
\end{tabular}

On average, a serving of chocolate (15.6 $\pm 6.2 \mathrm{~g}$ sugar)—applied to single serve only-contained just over half (52\%) of an adult's ( $30 \mathrm{~g} / \mathrm{d})$ and over two thirds $(65 \%)$ of a 7-10 year-old's $(24 \mathrm{~g} / \mathrm{d})$ maximum daily intake of sugar, with a range of 4.5 to $40.2 \mathrm{~g}$ 
The mean energy content in chocolate was $142 \pm 53 \mathrm{kcal} / \mathrm{serving}$. Chocolate confectionery with peanut butter filling contained the highest calorie content per serving $(222 \pm 62 \mathrm{kcal})$ and mint crisps $(62 \pm 28 \mathrm{kcal})$ contained the lowest (Table 4).

Among the single serve chocolate confectionery, only four products exceeded the maximum calorie cap of $250 \mathrm{kcal}$ per serving.

\subsubsection{Manufacturer}

Branded chocolate confectionery had a slightly higher sugar content compared with supermarkets' own labels, but the difference was not statistically significant (48.1 g vs. $46.5 \mathrm{~g}, p=0.125$ ).

Among the manufacturers with five or more chocolate products in this study (Table 5), Mars' product range contained the highest average sugar content and Moo Free's product range contained the highest energy content per $100 \mathrm{~g}$.

Table 5. Sugar and energy contents of chocolate confectionery by manufacturer per $100 \mathrm{~g}$ in 2017.

\begin{tabular}{|c|c|c|c|c|c|}
\hline Manufacturer & $\mathbf{N}$ & $\begin{array}{c}\text { Sugars (g) Mean } \pm \\
\text { SD (Range) }\end{array}$ & Manufacturer & $\mathbf{N}$ & $\begin{array}{c}\text { Energy (kcal) Mean } \pm \\
\text { SD (Range) }\end{array}$ \\
\hline Own label * & 284 & $46.5 \pm 11.9(1.2-75.2)$ & Own label * & 284 & $539 \pm 45(399-632)$ \\
\hline Branded ** & 243 & $48.1 \pm 12.2(0.5-67.9)$ & Branded ** & 243 & $526 \pm 52(121-647)$ \\
\hline \multicolumn{6}{|l|}{ Descending order } \\
\hline Mars & 29 & $55.3 \pm 6.0(44.8-67.9)$ & Moo Free & 5 & $579 \pm 7(568-585)$ \\
\hline Nestle & 42 & $54.8 \pm 7.3(29.4-66.4)$ & $\begin{array}{c}\text { Montezuma's } \\
\text { Chocolates }\end{array}$ & 8 & $576 \pm 15(547-601)$ \\
\hline Mondelez International & 55 & $54.3 \pm 5.5(45.0-65.5)$ & Lindt and Sprungli & 20 & $569 \pm 40(507-647)$ \\
\hline Aldi & 54 & $50.3 \pm 9.0(14.0-65.0)$ & Ferrero & 5 & $568 \pm 9(552-576)$ \\
\hline Lidl & 48 & $48.5 \pm 11.2(17.0-75.2)$ & Green and Black's & 13 & $566 \pm 27(510-630)$ \\
\hline Ferrero & 5 & $48.5 \pm 5.6(41.2-53.3)$ & Chocolate and Love & 5 & $565 \pm 19(547-598)$ \\
\hline Hershey Company & 7 & $48.1 \pm 4.8(41.8-54.4)$ & Doisy \& Dam & 5 & $560 \pm 10(547-570)$ \\
\hline ASDA & 24 & $46.5 \pm 10.5(16.0-60.0)$ & Moser Roth & 10 & $558 \pm 28(527-621)$ \\
\hline Waitrose & 16 & $45.5 \pm 12.2(27.6-67.0)$ & Marks and Spencer & 50 & $553 \pm 50(399-632)$ \\
\hline Morrisons & 25 & $45.4 \pm 10.1(16.4-63.1)$ & Heidi Chocolat Suisse & 6 & $551 \pm 35(515-600)$ \\
\hline Marks and Spencer & 50 & $45.2 \pm 11.4(16.0-73.0)$ & Waitrose & 16 & $551 \pm 60(411-628)$ \\
\hline Tesco & 29 & $44.8 \pm 13.2(12.9-67.0)$ & ASDA & 24 & $546 \pm 35(454-632)$ \\
\hline Sainsbury's & 37 & $43.1 \pm 16.4(1.2-67.0)$ & Morrisons & 25 & $541 \pm 46(451-619)$ \\
\hline Heidi Chocolat Suisse & 6 & $42.3 \pm 18.5(14.0-57.0)$ & Tesco & 29 & $538 \pm 37(452-604)$ \\
\hline Lindt and Sprungli & 20 & $41.9 \pm 12.9(7.0-57.0)$ & Hershey Company & 7 & $537 \pm 13(511-547)$ \\
\hline Moser Roth & 10 & $40.3 \pm 10.2(26.0-51.0)$ & Lidl & 48 & $536 \pm 48(427-630)$ \\
\hline Green and Black's & 13 & $39.2 \pm 10.6(13.5-51.0)$ & Sainsbury's & 37 & $533 \pm 41(444-596)$ \\
\hline Moo Free & 5 & $35.9 \pm 3.3(33.7-41.0)$ & Aldi & 54 & $528 \pm 41(417-608)$ \\
\hline Chocolate and Love & 5 & $35.8 \pm 10.5(19.0-47.0)$ & Nestle & 42 & $515 \pm 26(432-559)$ \\
\hline Doisy and Dam & 5 & $35.2 \pm 13.4(23.7-52.0)$ & $\begin{array}{c}\text { Mondelez } \\
\text { International }\end{array}$ & 55 & $510 \pm 41(363-560)$ \\
\hline Montezuma's Chocolates & 8 & $34.6 \pm 17.4(0.5-55.0)$ & Mars & 29 & $499 \pm 32(443-559)$ \\
\hline
\end{tabular}

\subsection{Comparison of Changes in Sugar Content between 1992 and 2017}

There were 23 products included in 1992 and 2017; the average sugar contents per $100 \mathrm{~g}$ were $44.6 \pm 9.4 \mathrm{~g}$ and $54.7 \pm 6.3 \mathrm{~g}(p<0.001)$ respectively, which represents an increase of $23 \%$.

\section{Discussion}

This study showed that the level of sugar in chocolate confectionery has increased since 1992, which is concerning from a public health nutrition perspective. Some may argue that the increase in sugar content was driven by consumer demand, but, as will be discussed later, marketing, advertisement and promotion of products also encourage demand for such products. Nonetheless, since products were lower in sugar in 1992, this may suggest that sugar can be reduced in chocolate confectionery. Without energy content data from 1992, it is difficult to be certain that these products were lower in energy as well as sugar compared to recent data. 
Nevertheless, the large variations in sugar and energy content within the same category of chocolate in 2017 suggests that reformulation is possible. For instance, some manufacturers produce chocolates with far less sugar and calories than their competitors, as illustrated in Table 3 by the broad ranges within each category. This demonstrates that the amount of sugar and energy can be reduced through reformulation because similar, lower sugar content products are already available on the market. This research also makes available data on the sugar and energy content of chocolate confectionery in the UK in 2017 for future evaluation of the recently launched government-led sugar reduction programme.

In order to better understand how some manufacturers are able to produce chocolate confectionery products with lower levels of sugar and thus meet the aims of the sugar reduction programme, it is important to understand the function of sugar in chocolate and what sugar replacements are used. Sugar is added to chocolate to contribute sweetness, but also because it is a cheaper ingredient than cocoa or other types of fat. It is reported that a change in sugar content by just $1 \%-2 \%$ has large cost implications, which is why manufacturers may be reluctant to reformulate $[15,16]$. However, looking at the 2017 data, it appears there are a few products with extremely low sugar content (as little as $0.5 \%$ ). Certainly, there have been studies to show that chocolate can be reformulated to reduce sugar and calories $[17,18]$.There are some potential barriers in place for the food industry which can hinder, to a certain point, a gradual reduction in sugar, namely the European sweeteners directive (EC, 1994), which does not permit the use of sugar and some sugar replacements, such as polyols, in the same recipe mix. In this circumstance, a reduction in portion size may offer more scope as a means to reduce sugar (and calorie) consumption in this category, as suggested by Public Health England [12]. Nevertheless, pressure to review the sweeteners directive (EC, 1994) will aid chocolate manufacturers in creating products with gradual reductions in sugar and also provide more choice for consumers.

Sugar-free chocolates have recently become popular because of reduced calorific value and the fact that they are both non-cariogenic and suitable for diabetics $[16,17]$. The negative publicity surrounding sugar could also have played a role in the fact that $28 \%$ of people report they limit the amount of chocolate they eat due to the high sugar content [18]. There are tentative signs that manufacturers and retailers are placing a greater focus on this. Chocolate products with a low/no/reduced sugar claim grew in 2015 and 2016, with activity mainly from branded manufacturers [18]. Indeed, it was seen from the 2017 survey that there were a few chocolate confectionery products with extremely low concentrations of sugar, as low as $0.5 \%$. However, these alternatives to well-known products, even after several years on the market, generally only account for a small proportion of sales and they are unlikely to change the market drastically [12].

In order to have a large impact, reformulation of existing products on the market is needed, owing to the huge volume of chocolate consumed; even small reductions would have a significant impact on sugar and energy intakes of the population. However, if the sugar reduction programme aimed to reduce childhood obesity, then perhaps the focus should be on the energy density of chocolate confectionery products and not just sugar content, because often the high-sugar products can be the lowest in energy content, as seen from the Nestle and Mars products in Table 5.

Furthermore, the 2017 survey showed that Mars, Nestle and Mondelez International are chocolate confectionery manufacturers with the highest sugar content on average. These are all multi-national companies, with large product portfolios. Some manufacturers may be reluctant to reformulate their products and reduce sugar and energy content due to fear of loss of sales. However, in recent years we have started to see many announcements of various reformulation efforts from such leading manufacturers [19].

In the future, a direct comparison could be made to track manufacturers' reformulation performances over time. It also allows researchers, policymakers and the industry to identify which manufacturers offers products with the highest sugar or energy content on average and the products with the narrowest range in sugar, energy or both, which suggests that these manufacturers are providing limited choice to their customers in terms of sugar levels or energy-density in their products. 
On the other hand, research shows that bigger and growing portion sizes result in more calories being consumed and it is estimated that if larger portions were removed from the diet completely, this could reduce energy intake by up to $16 \%$ [20]. Large serving sizes also distort the perception of what people view as a typical serving to consume [21,22]. Similarly, the recent increase in products sold in 'sharing bag' formats could encourage over-consumption of chocolate confectionery. The Grocer reported that one in four individuals do not share, but rather eat entire sharing bags themselves [23]. These can contain as much as $161 \mathrm{~g}$ sugar and $1142 \mathrm{kcal}$ in a single bag. This seems counterproductive to previous efforts by the industry to standardise single serve confectionery to a 250 calorie cap back in 2014 [24]. The 2017 data shows that on average all categories were below the $250 \mathrm{kcal}$ limit per serving. However, it is notable that, based on the ranges, the peanut butter filling and caramel-coated biscuit products are the two categories with products above this limit. In any case, while it is interesting to reflect on the energy content of single-serve products, these products are in decline, with 'sharing bags' and block chocolate now driving growth [25]. Since these formats are increasingly popular, manufacturers should look at packaging that encourages sharing or reduces the amount consumed in one go, e.g. resealable packs [26].

Furthermore, efforts may be hindered by the fact that the UK does not have standardised serving sizes for chocolate confectionery, unlike other countries such as Australia (set at $25 \mathrm{~g}$ ) [27], the US and Canada (set at $40 \mathrm{~g}$ ) [28,29]. As shown in this study, there is a lack of consistency among serving sizes of similar products, therefore manufacturer-recommended serving sizes are not always comparable across similar products and not always consistent with the portion size that consumers actually eat [30]. Displaying per serving and per pack information may confuse consumers and overcomplicate the information provided on packaging [30].

Therefore, consistent serving sizes that are aligned with dietary guidelines have the potential to gradually change norms to encourage healthier eating habits and could have a meaningful effect on population health [31]. Indeed, it may be timely that in Public Health England's recent published analysis of the chocolate confectionery market, considered a single serve of chocolate confectionery as chocolate confectionery above $10 \mathrm{~g}$ or below $60 \mathrm{~g}$ [12]. To take this further, manufacturers should agree on a typical serving for similar formats, for example, a reasonable serving of chocolate confectionery in a sharing bag or a block of chocolate. Our data showed that not many products exceeded the maximum calorie cap per serve of $250 \mathrm{kcal}$ [12]. This suggests the cap is not challenging enough and should be lowered.

In terms of sales, chocolate bars and blocks remain the top choices, each eaten by nearly two thirds of chocolate consumers [27]. Therefore, targeting those products with reformulation and portion size reduction may be the key in helping manufacturers reach their $20 \%$ reduction target. As seen from the 2017 data, there is a large variation in similar block chocolate products on the market per $100 \mathrm{~g}$, such as white, dark and milk chocolate, which suggests there is scope to reduce sugar in these products, as well as energy. There is opportunity to reduce intake in these categories; $39 \%$ of chocolate consumers say a smaller portion/pack size would be a good alternative to a reduction in sugar [18]. However, transparency will be key to ensuring buy-in of such changes and to avoid consumer backlash, because $76 \%$ of consumers think chocolate brands should make it clear when they reduce the size/weight of the pack [18].

Aside from reformulation and portion size restrictions, evidence shows that consumption of chocolate is influenced by advertising and marketing [32]. Brands with high advertising spends see higher sales [33]. In 2016 there was an upsurge in advertising spend [18]. Advertising expenditure on chocolate confectionery increased by $15 \%$ in 2016, reaching £126 million in total [18]. Furthermore, many confectionery brands sponsor major sporting events, creating a unique marketing opportunity for them to boost sales. Cadbury, for instance, sponsored the London 2012 Olympics [34] and the Premier League in 2017/18 [34], whilst the England team sponsor was Mars during the UEFA (Union of European Football Associations) Euro 2016 tournament. Mars heavily promoted its range during and after the tournament in stores [35]. Therefore, introducing advertisement restrictions based on sugar 
or energy contents of products could also incentivise manufacturers to reformulate their products in order to advertise them.

Finally, another area that can have an impact on chocolate confectionery sugar content is front of pack nutrition labelling. This study showed that a high proportion of products would be labelled as red for sugars. If such a labelling system was enforced, some manufacturers may be incentivised to reformulate in order to avoid putting red labels on their products.

Increasingly, companies are calling for government-led regulations, since voluntary agreements are always led by progressive companies, often putting them at an economic disadvantage. Recently, Chairman and then-CEO of Nestle, Dame Fiona Kendrick, insisted the voluntary approach to tackling childhood obesity, as laid out by Public Health England, would not go far enough and called for government regulation to tackle the health crisis [26]. Various regulations, perhaps similar to the Soft Drinks Industry Levy, could be applied to encourage reformulation.

While there are many worthwhile findings in this study, it is important to acknowledge some of the limitations. The 1992 sugar content data used in this study was from a booklet published in 1992 . We assumed the data included was a comprehensive representation of the products available on the UK market at the time. However, we are unable to verify this.

The 2017 data used were based on sugar and energy content data provided on product packaging labels in-store; hence, we relied on the accuracy of the data provided on the label. However, further studies could include sugar and energy contents determined through laboratory analysis to determine the accuracy of labels.

Furthermore, since we assumed the total sugars labelled on packaging was predominately free sugars, we may have overestimated the amount of free sugars in products that contained milk and/or dried fruit. Future analysis should seek to calculate the amount of milk and/or dried fruit used in a product to better understand the actual free sugars content of the product. This can be done by asking manufacturers to share their recipes or the amount of sugar and other ingredients used per $100 \mathrm{~g}$.

This study did not analyse the fat, saturated fat, carbohydrate or protein contents of chocolate confectionery, but did collect and analyse total energy content in 2017, which would include the amount of energy coming from all these nutrients; therefore, any potential future reductions in the amount of energy can be from reductions in other nutrients too, as well as sugar.

Nevertheless, the results of this study are relevant and serve to document the sugar and energy content of chocolate confectionery sold in the UK, providing data to evaluate public health interventions, such as the Government's sugar reduction programme, and act as an incentive for the chocolate confectionery industry to reformulate their products.

\section{Conclusions}

The results show that the sugar content of chocolate confectionery has increased since 1992, which is concerning from a public health perspective. However, the results also suggest that sugar levels can be reduced because (a) lower sugar versions of the same products existed in 1992 and (b) there is a large variation in sugar and energy content between different categories of chocolate and within the same category. This research also makes available data of the chocolate confectionery market in the UK for evaluation of the recently launched sugar reduction programme. A reduction in sugar and energy content and overall chocolate confectionery consumption could help reduce overall sugar and energy intake in the UK.

Author Contributions: Conceptualization, K.M.H.; methodology, K.M.H. and S.A.A.; software, K.M.H. and F.J.H.; data curation, K.M.H. and S.A.A.; writing-original draft preparation, K.M.H.; writing-review and editing, K.M.H., F.J.H., S.A.A. and G.A.M.; visualization, K.M.H.; supervision, F.J.H.

Funding: This research received no external funding.

Acknowledgments: We would like to thank Jack Winkler for providing us with a copy of the chocolate confectionery section of the Octavo A-Z of Shopping; Guide to Good Health. What's in your shopping basket? booklet. 
Conflicts of Interest: F.J.H. is a member of Action on Salt (AOS) and its international branch Word Action on Salt and Health (WASH). F.J.H. does not receive any financial support from AOS and WASH. G.A.M. is Chairman of Blood Pressure UK (BPUK), WASH and Action on Salt, Sugar and Health (CASSH). K.M.H. is an employee of CASSH. All the other authors declare no competing interest.

\section{Appendix A}

The following products contributed to the company averages and overall results but not category results, because they did not fit into a specific category.

Mars Revels $112 \mathrm{~g}$

$\mathrm{M}$ and M's Peanut $250 \mathrm{~g}$

Nestle Caramac 4 bars

$\mathrm{M}$ and M's Pretzel Chocolate Candies $32.3 \mathrm{~g}$

Cadbury Dairy Milk Mixed Buttons $115 \mathrm{~g}$

Nestle Caramac Giant Buttons $110 \mathrm{~g}$

M and S Milk Chocolate Covered Pretzels \& Popping Candy Popcorn $120 \mathrm{~g}$

Nestle Pick and Mix $107 \mathrm{~g}$

Marks and Spencer Milk Chocolate Coated Pretzels $60 \mathrm{~g}$

Mars Revels $101 \mathrm{~g}$

Mars Revels $173 \mathrm{~g}$

$\mathrm{M}$ and M's Peanut $140 \mathrm{~g}$

Revels Treat Bag $78 \mathrm{~g}$

Nestle Pick and Mix $107 \mathrm{~g}$

\section{References}

1. Public Health England. Why 5\%? 2015. Available online: https://www.gov.uk/government/uploads/system/ uploads/attachment_data/file/446010/Why_5____The_Science_Behind_SACN.pdf (accessed on 1 July 2017).

2. SACN. Carbohydrates and Health. 2015. Available online: https://wwwgovuk/government/uploads/system/ uploads/attachment_data/file/445503/SACN_Carbohydrates_and_Healthpdf (accessed on 2 March 2018).

3. Romaguera, D.; Norat, T.; Wark, P.A.; Vergnaud, A.C.; Schulze, M.B.; van Woudenbergh, G.J.; Drogan, D.; Amiano, P.; Molina-Montes, E.; Sanchez, M.J.; et al. Consumption of sweet beverages and type 2 diabetes incidence in European adults: Results from EPIC-InterAct. Diabetologia 2013, 56, 1520-1530. [CrossRef] [PubMed]

4. De Koning, L.; Malik, V.S.; Rimm, E.B.; Willett, W.C.; Hu, F.B. Sugar-sweetened and artificially sweetened beverage consumption and risk of type 2 diabetes in men. Am. J. Clin. Nutr. 2011, 93, 1321-1327. [CrossRef] [PubMed]

5. Maki, K.C.; Phillips, A.K. Dietary substitutions for refined carbohydrate that show promise for reducing risk of type 2 diabetes in men and women. J. Nutr. 2015, 145, 159S-163S. [CrossRef] [PubMed]

6. Feinman, R.D.; Pogozelski, W.K.; Astrup, A.; Bernstein, R.K.; Fine, E.J.; Westman, E.C.; Accurso, A.; Frassetto, L.; Gower, B.A.; McFarlane, S.I.; et al. Dietary carbohydrate restriction as the first approach in diabetes management: Critical review and evidence base. Nutrition 2015, 31, 1-13. [CrossRef] [PubMed]

7. Te Morenga, L.; Mallard, S.; Mann, J. Dietary sugars and body weight: Systematic review and meta-analyses of randomised controlled trials and cohort studies. BMJ 2013, 346, e7492. [CrossRef] [PubMed]

8. Johnson, R.K.; Appel, L.J.; Brands, M.; Howard, B.V.; Lefevre, M.; Lustig, R.H.; Sacks, F.; Steffen, L.M.; Wylie-Rosett, J. Dietary sugars intake and cardiovascular health: A scientific statement from the American Heart Association. Circulation 2009, 120, 1011-1020. [CrossRef] [PubMed]

9. Xi, B.; Li, S.S.; Liu, Z.L.; Tian, H.; Yin, X.X.; Huai, P.C.; Tang, W.H.; Zhou, D.H.; Steffen, L.M. Intake of Fruit Juice and Incidence of Type 2 Diabetes: A Systematic Review and Meta-Analysis. PLoS ONE 2014, 9, e93471. [CrossRef] [PubMed]

10. Moynihan, P.J.; Kelly, S.A. Effect on Caries of Restricting Sugars Intake: Systematic Review to Inform WHO Guidelines. J. Dent. Res. 2014, 93, 8-18. [CrossRef] [PubMed]

11. Public Health England. NDNS: Results from Years 5 and 6 (Combined). 2016. Available online: https: //www.gov.uk/government/statistics/ndns-results-from-years-5-and-6-combined (accessed on 2 June 2017). 
12. Public Health England. Sugar Reduction: Achieving the $20 \%$. 2017. Available online: https://www.gov.uk/ government/publications/sugar-reduction-achieving-the-20 (accessed on 20 December 2017).

13. Kantar Worldpanel. Grocery Market Share-Kantar Worldpanel. 2016. Available online: http://www. kantarworldpanel.com/en/grocery-market-share/great-britain (accessed on 20 June 2017).

14. Department of Health. Guide to creating a front of pack (FoP) nutrition label for pre-packed products sold through retail outlets. 2016. Available online: https://www.food.gov.uk/sites/default/files/multimedia/pdfs/ pdf-ni/fop-guidance.pdf (accessed on 1 July 2017).

15. Beckett, S.T. Industrial Chocolate Manufacture and Use, 3rd ed.; Blackwell Science: Oxford, UK, 1999.

16. Afoakwa, E.O.; Paterson, A.; Fowler, M. Factors influencing rheological and textural qualities in chocolate-A review. Trends Food Sci. Technol. 2007, 18, 290-298. [CrossRef]

17. Sokmen, A.; Gunes, G. Influence of some bulk sweeteners on rheological properties of chocolate. LWT Food Sci. Technol. 2006, 39, 1053-1058. [CrossRef]

18. Mintel. Chocolate Confectionery UK 2017. Available online: https://store.mintel.com/chocolateconfectionery-uk-may-2017 (accessed on 6 March 2018).

19. Nestle. Nestlé UK \& Ireland to Strip Out 10\% of Sugar from Confectionery Range. 2017. Available online: https://www.nestle.co.uk/media/pressreleases/stepping-up-to-the-sugar-challengeuk (accessed on 22 May 2019).

20. Hollands, G.J.; Shemilt, I.; Marteau, T.M.; Jebb, S.A.; Lewis, H.B.; Wei, Y.; Higgins, J.; Ogilvie, D. Portion, package or tableware size for changing selection and consumption of food, alcohol and tobacco. Cochrane Database Syst. Rev. 2015. [CrossRef] [PubMed]

21. Schwartz, J.; Byrd-Bredbenner, C. Portion Distortion: Typical Portion Sizes Selected by Young Adults. J. Am. Diet. Assoc. 2006, 106, 1412-1418. [CrossRef] [PubMed]

22. Young, L.R.; Nestle, M. Reducing Portion Sizes to Prevent Obesity: A Call to Action. Am. J. Prev. Med. 2012, 43, 565-568. [CrossRef] [PubMed]

23. The Grocer. Revealed: One in Four Binge on Chocolate Sharing Bags. $2014 . \quad$ Available online: https://www.thegrocer.co.uk/reports/digital-features/confectionery-report-2014/revealed-one-infour-binge-on-chocolate-sharing-bags/369836.article (accessed on 6 October 2017).

24. Nieburg, O. The Death of Kingsize? UK Confectioners Agree 250 Calorie Cap. 2014. Available online: http://www.confectionerynews.com/Manufacturers/250-calorie-cap-agreed-by-UK-confectioners (accessed on 6 September 2017).

25. The Grocer. Sharing Formats Hit the Sweet Spot as Singles Suffer. 2016. Available online: https://www.thegrocer.co.uk/reports/digital-features/confectionery-report-2016/sharing-formats-hitthe-sweet-spot-as-singles-suffer/538864.article (accessed on 4 June 2018).

26. The Grocer. In Need of Divine Inspiration: Chocolate Category Report 2017. 2017. Available online: https://www.thegrocer.co.uk/reports/category-reports/in-need-of-divine-inspiration-chocolate-categoryreport-2017/558093.article (accessed on 6 June 2018).

27. Watson, W.L.; Kury, A.; Wellard, L.; Hughes, C.; Dunford, E.; Chapman, K. Variations in serving sizes of Australian snack foods and confectionery. Appetite 2016, 96, 32-37. [CrossRef] [PubMed]

28. U.S. Food and Drug Administration. Code of Federal Regulations Title 21. US Department of Health \& Human Resources. 2017. Available online: https://www.accessdata.fda.gov/scripts/cdrh/cfdocs/cfcfr/ CFRSearch.cfm?CFRPart=312\&showFR=1 (accessed on 1 August 2018).

29. Canadian Food Inspection Agency. Information within the Nutrition Facts Table, Reference Amounts. Government of Canada, 2012. Available online: http://inspection.gc.ca/food/labelling/food-labellingfor-industry/nutrition-labelling/information-within-the-nutrition-facts-table/eng/1389198568400/ 1389198597278? chap=5 (accessed on 6 June 2017).

30. Faulkner, G.P.; Pourshahidi, L.K.; Wallace, J.M.W.; Kerr, M.A.; McCrorie, T.A.; Livingstone, M.B.E. Serving size guidance for consumers: Is it effective? Proc. Nutr. Soc. 2012, 71, 610-621. [CrossRef] [PubMed]

31. Gortmaker, S.L.; Swinburn, B.A.; Levy, D.; Carter, R.; Mabry, P.L.; Finegood, D.T.; Huang, T.; Marsh, T.; Moodie, M.L. Changing the future of obesity: Science, policy, and action. Lancet 2011, 378, 838-847. [CrossRef]

32. Public Health England. Sugar Reduction: The Evidence for Action. 2015. Available online: https://www.gov.uk/government/uploads/system/uploads/attachment_data/file/470179/Sugar_reduction_ The_evidence_for_action.pdf (accessed on 4 October 2018). 
33. Obesity Health Alliance. Health Costs of Obesity Soaring as Junk Food Companies Pour Millions into Advertising. 2017. Available online: http://obesityhealthalliance.org.uk/2017/10/11/press-release-healthcosts-obesity-soaring-junk-food-companies-pour-millions-advertising/ (accessed on 1 December 2017).

34. Premier League. The Premier League and Cadbury Have Come Together to Start an Exciting Partnership, Kicking off from the Start of the 2017/18 Season. 2017. Available online: https://www.premierleague.com/ partners/cadbury (accessed on 1 September 2018).

35. Brandview. Grocery Retailers Unfazed by Which? Research Findings into 'Unhealthy Promotions'. 2016. Available online: http://www.brandview.com/2016/08/grocery-retailers-unfazed-by-which-researchfindings-into-unhealthy-promotions/ (accessed on 1 June 2018).

(C) 2019 by the authors. Licensee MDPI, Basel, Switzerland. This article is an open access article distributed under the terms and conditions of the Creative Commons Attribution (CC BY) license (http://creativecommons.org/licenses/by/4.0/). 